\title{
Effect of Hybrid Modification and Type of Compaction on the Cracking Properties of Asphalt Concrete
}

\author{
Mohammed A. Abed ${ }^{1}$ and Alaa H. Abed ${ }^{2 *}$
}

\section{Authors Affiliations:}

1) Civil Eng. Dept., AlNahrian Univ. Baghdad, Iraq. eng.mohammedassi@gmail. $\underline{\mathrm{com}}$

$\left.2^{*}\right)$ Civil Eng. Dept., AlNahrian Univ. Baghdad, Iraq.

alaa.abed@eng.nahrainuniv. edu.iq, alaah29@yahoo.com

\section{Paper History:}

Received: $13^{\text {th }}$ Oct. 2019

Revised: $29^{\text {th }}$ Dec. 2019

Accepted: $16^{\text {th }}$ March 2020

\begin{abstract}
This paper focused on evaluating the effect of aggregate gradation and polymer modification on indirect tensile strength (ITS) and the static stiffness for hot asphalt mixtures. In particular, data from ITS tests have been processed to obtain stiffness measurements through the application of Hondros theory. The results showed that fine mixtures had a better tensile strength by $26.3 \%$ than the coarse mixtures. The effect of compaction also was examined, the results showed that samples compacted with the Superpave gyratory compactor (SGC) had an enhancement in ITS by 36.58 and $23.1 \%$ in comparison with Marshall and roller compactor respectively. Polymer modifiers were used to estimate their effect on tensile strength, adding 4, 6, and $8 \%$ of Styrene-Butadiene-Styrene (SBS), which can rise the ITS by 3.2,6.14 and $13.3 \%$ of the non-modified asphalt mixture. Furthermore, using 4, 6, and 8 percent of SBS could increase static stiffness by $53.9,209.6$, and $302.4 \%$ respectively for roller compacted fine mixes and 58, 220, and $379.3 \%$ for SGC compacted mixes. Furthermore, SBS raised the stiffness modulus by 52.3, 188, and 295\% for Marshall compacted mixes. Using hybrid modifier can improve the stiffness of the asphalt mixture. However, The results indicate that using 1,2 and 3\% polyvinyl chloride (PVC) can magnify the stiffness of mixtures by $41.2,199.8 \%$ and 262.6 for roller compacted mixtures and 133.4, 212.1 and $354 \%$ for SGC compacted mixtures, whereas there is a stringent increasing by $133.4,189.2$ and $354 \%$ for Marshall compacted mixes. Otherwise, polymer-modification can decrease the fracturing index for coarse and fine mixtures
\end{abstract}

Keywords: Indirect Tensile Strength, Hondros Theory, SBS, Static Stiffness

$$
\begin{aligned}
& \text { تأثير المضافات الهجينة ونوع الحدل على خصائص التشققات في الخرسانة الاسفتية }
\end{aligned}
$$

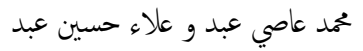

$$
\begin{aligned}
& \text { ركزت هذه الورقة على تقييم تأثير تدرج الركام و المضافات البولميرية على قوة الشد غير المباشرة (ITS) والصلابة الساكنة }
\end{aligned}
$$

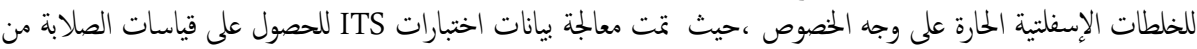

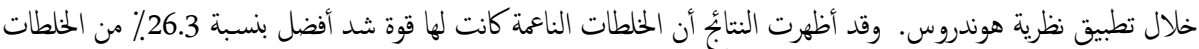

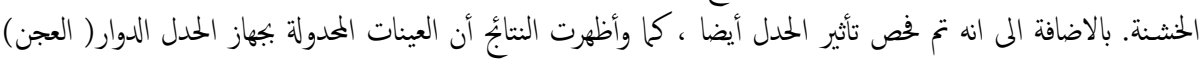

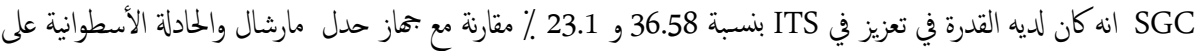

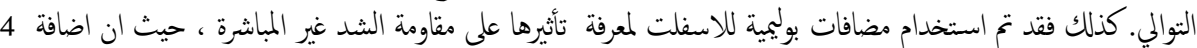

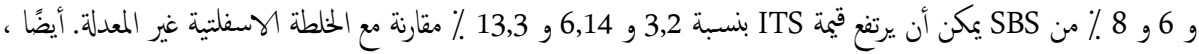

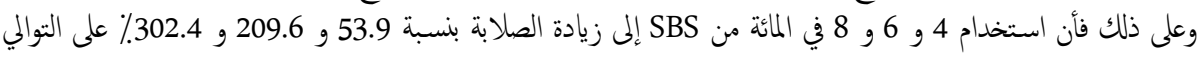

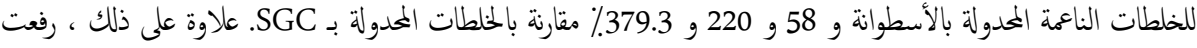

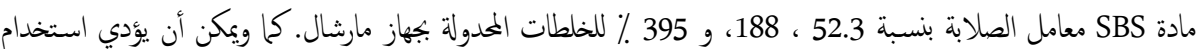

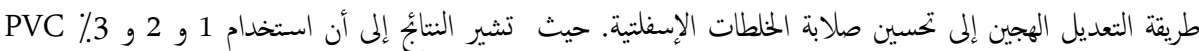

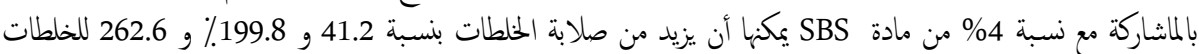

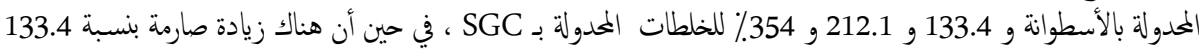

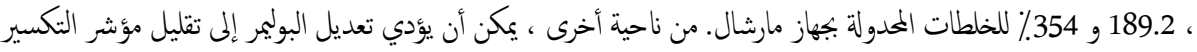

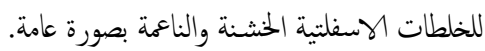

NJES is an open access Journal with ISSN 2521-9154 and eISSN 2521-9162

This work is licensed under a Creative Commons Attribution-NonCommercial 4.0 International License 


\section{Introduction}

Tensile strength is considered a substantial matter in the performance of the asphalt concrete under prevailing conditions and moisture sensitivity $[1,2]$. In general, the tensile strength of hot mix asphalt is the primary function of the asphalt binder characteristics and aggregate morphology [3, 4]. At specified asphalt content, particle-to-particle contact and the film thickness of asphalt on the surface of aggregates play a key role in the adhesion characteristics or tensile strength of the asphalt mixtures[5]. Some specific types of pavement distresses are related to the rheological properties of asphalt cement [6, 7]. Correspondingly, in road pavement, asphalt binder modification has been implemented over the world to ameliorate the performance of the conventional pavement[8]. Modified asphalt mixture can engender real interests in road re-habitations or constructions in terms of perfect and longer life roads, and economical issues in pavement maintenance[9]. Many researchers have investigated the effect of modification for asphalt concrete in term of binders or mixtures to make general indication about the influence of modifiers on the rheological attributes and fatigue resistance with the aim of preventing fatigue cracking in asphalt pavements [5, 10]. Polacco et al.[11] Stated that Polymer-modified asphalt (PMA) originate their conceptual and technological derivation from the need for increasing the performance and durability of asphaltic constituents as well as increasing their adhesion to mineral aggregates. Tayfur et al., [12] and Sengoz and Isyikaar [13] stated that the optimum asphalt ratios of Styrene-Butadiene-Styrene (SBS) modified asphalt mixes were much higher than the conventional mixture. To optimize the determination of the aggregates array, uniformly distribution the binders and air voids, and minimize residual air voids, the process of compaction should be specified [14]. Furthermore, the mechanical behavior of mixtures fabricated with various compaction instruments has been widely considered [15]. Button et al. 1994[16], summarized that the mechanical behavior of asphaltic mixes with stiff bitumens was comparatively unaffected by compaction. Harvey et al. 1994, summarized that the air void was affected by the compaction effort and is one of the most significant factors affecting the tensile strength of compacted asphalt concrete [17].

Nevertheless, tensile resistance is a vital consideration for hot asphalt mixtures design [18]. Cracking of asphalt pavements is widespread due to such reasons such as (i) extreme traffic load, (ii) poor design, and (iii) use of stiff asphalt mixtures in the pavement layers [18-20]. The current Superpave volumetric-based mixture design method barely considers the performance of asphalt mixes[21]. On the other hand, asphalt mixtures are becoming more complex with the growing use of recycled or reclaimed materials, additives, and modifiers. Thus, it is very vital to riddle asphaltic materials according to their performance to achieve the deliberated design life. Various cracking tests have been recognized in the comprehensive review of literature accomplished by the National Cooperative Highway Research Program (NCHRP) 9-57[22].

The ASTM postulate various configurations for testing and determining the stiffness of asphaltic mixtures, such as direct tensile tests bending tests, and indirect tensile tests. Amid these techniques, modulus testing in indirect tension methods is currently prevalent, as it is straightforward to be executed and can be accomplished both on field-cored and laboratory fabricated specimens. To embrace a convenient technique in assessing relative properties of hot asphaltic mixes (HMA), the hot mix asphalt was assumed as homogenous, isotropic, and elastic materials. The Hondros' theory [23] suggests the solution of the elastic issue for the cylindrical specimens exposed to a static indirect tension force [24]. Almudaiheem and Al-Sugair [24, 25] detected that indirect tensile stiffness modulus (ITSM) magnitude concern with the indirect tensile strength percentage which used a utilized load. Pan et al. [26] illustrate that the coarse aggregate morphology meaningfully impacts on the ITSM. Eventually, numerous authors stated $[27,28]$ that ITSM substantially is contingent on the thickness and diameter of the specimens. This paper focuses on evaluating the effect of aggregate gradation, polymer modification, compaction type, on the cracking attributes of HMA. Also transmutation the data acquired from the indirect tensile test (IDT) to attain the static stiffness for modified and conventional asphalt mixtures by applying the Hondros theory. Furthermore, employing the IDT test to achieve as the IDEAL-CT. In conclusion, this research deduces the IDEAL-CT appoint to be a cracking principles in form of fracturing index.

\section{Materials and Methodology}

Two gradations mixes were used in this study as shown in Fig. 1 to reveal the effect of aggregate tensile properties, referred as coarse and fine mix which specified by the State Commission of Road and Bridges (SCRB), Iraq[29], one performance grade asphalt (PG 64-16) and two types of polymers were used with different percentages to show their effect on locally produced asphalt. The two types of polymers which were used in this work are: the Styrene Butadiene-styrene (SBS), and polyvinyl copolymer (PVC), with three percents for each type of polymer (1, 2 and 3 percents) for PVC while the percentage of modification for SBS are (4, 6 and $8 \%$ ). In particular, optimum asphalt contents were found to be coarse and fine mixes $(4.6 \%)$ and $(4.8 \%)$ respectively by weight of aggregate. 42 asphaltic samples of $15 \mathrm{~cm}$ in diameter with a thickness of $8.7 \mathrm{~cm}$, were compacted Superpave gyratory compactor according to AASHTO T-312 as shown in Fig. 2a. Furthermore, AC specimens (coarse and fine) were fabricated by two different compaction mods (Marshall and roller compactor) which were also used to examine the influence of compactions modes on the tensile strength of hot mixes.108 specimen (10.1 cm of diameter by $6.2 \mathrm{~cm}$ of thick) were fabricated by a Marshall compactor according to AASHTO designation R 68 as shown in Fig. 2b. Besides, ten specimens of slabs ( 40 by $30 \mathrm{~cm}$ ) were also fabricated using roller compactor according to ASTM 
D 8079 (as shown in Fig. 2c) to detect the effect of confinement on indirect tensile strength. Some of these sample are shown in Fig. 3.

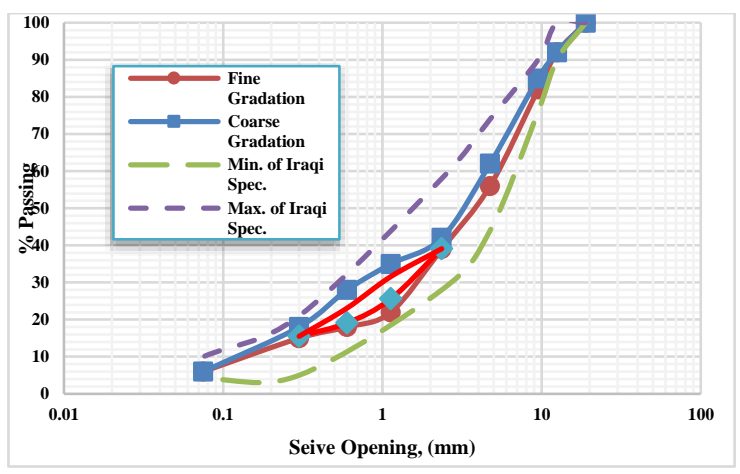

Figure (1). Mixes gradation

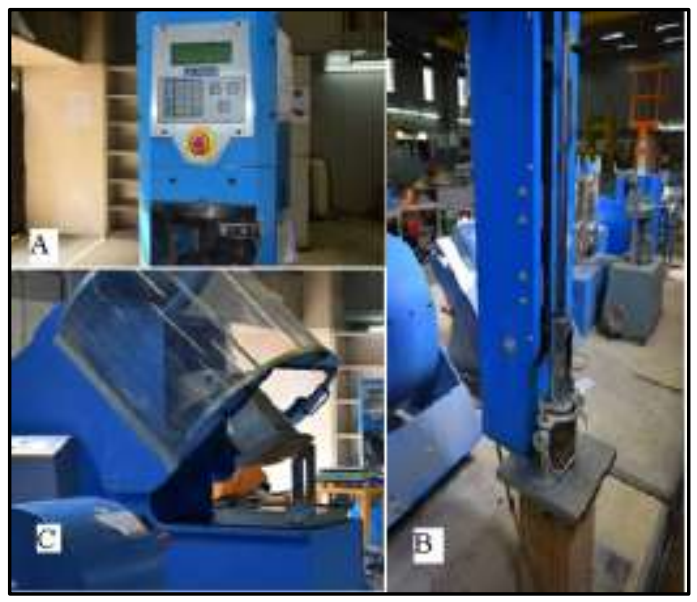

Figure (2). Apparatuses of Compaction
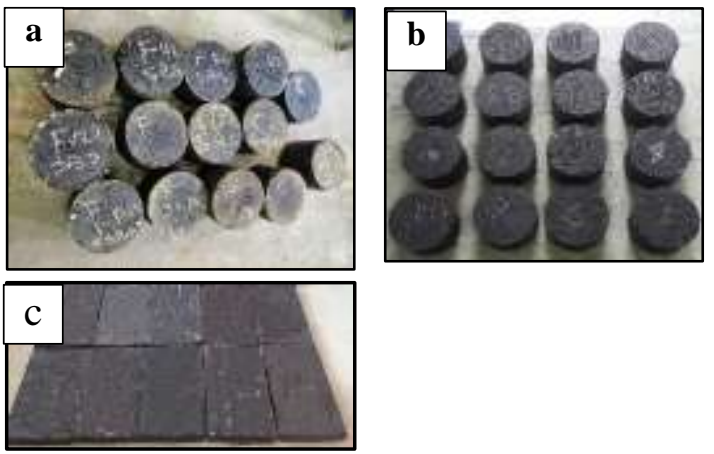

Figure (3) Prepared Specimens a) SGC, b) Marshall c) Roller Compactor

The indirect tensile test was accomplished by loading a cylindrical specimen with a monocular loading, which implemented in matching with the vertical diametric plane. This compression loading configuration induces a comparatively uniform tensile stress perpendicular to the direction of the applied compression load and along the vertical diametrical plane, which essentially causes a splitting along the vertical diameter as shown in Fig. 4 and 5. The curved loading auxiliaries were utilized to supply uniform loading dimensions, which provide relatively uniform stress distribution. The applied load was at a constant rate of $5.08 \mathrm{~cm} / \mathrm{min}$. $(50.8 \mathrm{~mm} / \mathrm{min})$ and the ultimate load at collapse or failure were documented.
Generally, the indirect tensile strength (ITS) is calculated according to equation (1) [30], as follows:

$$
\text { ITS }=\frac{\mathbf{P u}}{\boldsymbol{\pi} \times \mathbf{r} \times \mathbf{t}}
$$

Where:

ITS $=$ Indirect tensile strength in $(\mathrm{kPa})$.

$\mathrm{P}_{\mathrm{u}}=$ Ultimate load at failure in $(\mathrm{kN})$.

$r=$ The specimen radius in $(\mathrm{m})$, and

$\mathrm{T}=$ Specimen Thickness in (m).

Moreover, the surface deflection induced were recorded with time to be used in subsequent special calculations. The specimens are used for this test is the simple cored Gyratory according to ASTM D5361, roller compacter and Marshall specimens. Irregularities of the surface had not extremely affected the results. This test was practised at $25^{\circ} \mathrm{C}$ on briquettes both on the conventional and modified mixture. Deformation values and Durations of the test load and were recorded until the splitting point. Poisson ratio was assumed as 0.35 similar to other researchers and calculated horizontal deformations[24].
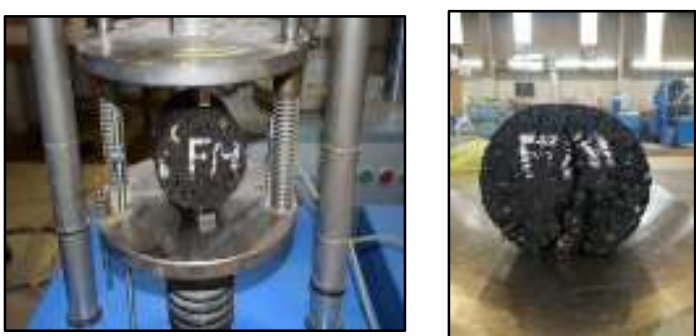

Figure (4) Indirect Tensile Test

\subsection{The Hondros' Theory}

The Hondros' theory provides the solution for the elastic problem on a cylindrical specimen undergo to a fixed indirect tension load. It offers a calculation for the vertical and horizontal stresses on the inclusive coordination of $y$ for the diameter (the origin of the axes is fixed in the center of the specimen) [23, 24]. It has to focus on that in the present study, the Hondros' solution was utilized merely to assess the stress state of the specimen diametrically, below the loading auxiliaries. This is associated with the statement that through the static indirect tensile experiments only the vertical displacement could be measured a mentioned in ASTM D6931, such a methodology is different from the one defined in the stress-strain state is studied along the horizontal diameter. The vertical superficial changing $\Delta \mathrm{U}_{\mathrm{y}}$ can be calculated by integrating the vertical responses $\varepsilon_{y y}$ on the vertical diameter. With the hypothesis of isotropic, homogeneous, and linear elastic material, $\varepsilon_{y y}$ could be determined by the generalized Hooke's equations. Hence, $\Delta \mathrm{U}_{\mathrm{y}}$ could be obtained by equation (2):

$$
\Delta \mathrm{U}_{\mathrm{y}}=\int_{\frac{-\mathrm{D}}{2}}^{\frac{\mathrm{D}}{2}} \varepsilon_{\mathrm{yy}} \mathrm{dy}=\int_{\frac{-\mathrm{D}}{2}}^{\frac{\mathrm{D}}{2}}\left[\frac{1}{\mathrm{E}}(\sigma \mathrm{yy}-\mu \sigma \mathrm{xx})\right] \mathrm{dy}
$$

The formula for the determination of $\Delta \mathrm{Uy}$ can be obtained as such a function is quite complicated to be managed. The integral is solved numerically, 
discretizing the vertical diameter in 100 elements $\mathrm{m}$. Therefore, the integral can be changed in the summation of equation 3 .

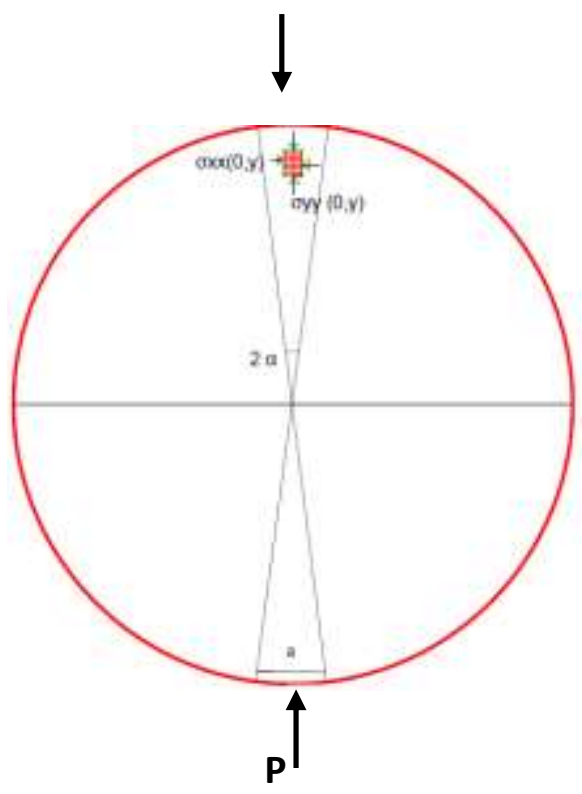

Figure (5) Load scheme of Indirect Tensile strength

$$
\begin{aligned}
& \Delta \mathrm{Uy}_{\mathrm{y}}=\frac{1}{\mathrm{E}} \frac{2 \mathrm{P}}{\pi \mathrm{ah}}\left\{\frac { \mathrm { D } } { \mathrm { m } } \sum _ { \mathrm { i } = 1 } ^ { \mathrm { m } } \left[\frac{1-\left(\frac{\mathrm{y}}{\mathrm{R}}\right)^{2}}{1-2\left(\frac{\mathrm{y}}{\mathrm{R}}\right)^{2} \cos 2 \alpha+\left(\frac{\mathrm{y}}{\mathrm{R}}\right)^{4}}+\right.\right. \\
& \left.\tan ^{-1}\left(\frac{1+\left(\frac{\mathrm{y}}{\mathrm{R}}\right)^{2}}{1-\left(\frac{\mathrm{y}}{\mathrm{R}}\right)^{2}} \tan \alpha\right)\right]- \\
& \mu \frac{\mathrm{D}}{\mathrm{m}} \sum_{\mathrm{i}=1}^{\mathrm{m}}\left[\frac{1-\left(\frac{\mathrm{y}}{\mathrm{R}}\right)^{2}}{1-2\left(\frac{\mathrm{y}}{\mathrm{R}}\right)^{2} \cos 2 \alpha+\left(\frac{\mathrm{y}}{\mathrm{R}}\right)^{4}}+\right. \\
& \left.\left.\tan ^{-1}\left(\frac{1+\left(\frac{\mathrm{y}}{\mathrm{R}}\right)^{2}}{1-\left(\frac{\mathrm{y}}{\mathrm{R}}\right)^{2}} \tan \alpha\right)\right]\right\}
\end{aligned}
$$

To simplify this equation, equation 4 is the final expression;

$$
\Delta \mathrm{U}_{\mathrm{y}}=\frac{1}{\mathrm{E}} \frac{2 \mathrm{P}}{\pi \mathrm{ah}} \mathrm{C}
$$

Where:

$\mathrm{P}=\operatorname{vertical} \operatorname{load}(\mathrm{N})$;

$\mathrm{h}=$ specimen height; and

$\mathrm{R}=$ specimen radius;

$\mathrm{a}=$ the width of load strip; and

$2 \alpha=$ center of the angle subtended by the loading strip as shown in Fig. 5.

$\mathrm{C}=$ the approximate magnitude of the curly brackets of equation 4, which depends on the specimen geometry, test fixtures dimensions and the Poisson ratio which is considered as 0.35 according to recent researches[24, 31]. However, former researches proved that Poisson's ratio for Asphaltic mixtures has a viscoelastic behavior, which can almost fluctuate amid 0.20 and 0.45 in association with frequency and temperature. By reversing the preceding relation, Hondros static modulus $\mathrm{E}_{\mathrm{s}, \mathrm{H}}$ could be calculated by equation 5:

$$
\mathrm{E}_{\mathrm{s}, \mathrm{H}}=\frac{1}{\mathrm{Uy}} \frac{2 \mathrm{P}}{\pi \mathrm{ah}}(\mathrm{C})
$$

This solution permits the acquisition of an elastic modulus, whereas the considerable deformations formulated in the vertical direction are non-elastic, hence important to underrate stiffness values. However, these moduli are still useful to do preparatory and prorated evaluations between various mixtures and materials.

\subsection{Testing Program}

The testing program of this study where recognize the effect of considerable parameters effecting on ITS of HMA such as aggregate gradation, asphalt content, temperature, compaction type, modification type and percent of modification.

The factors were adopted to prepare the asphalt concrete mixtures for most tests were two optimum asphalt contents of (4.6) \% by weight of mixture for coarse mixtures and (4.8) \% by weight of aggregate for the fine mixture as suggested by the SCRB[29] specification of wearing course were used to evaluate the effect many variables on the indirect tensile strength the static stiffness of these mixtures. One performance grade binder (PG64-16) from Al-Dourah refinery was used, as well as three types of additives which were the styrene butadiene styrene (SBS), with $(4,6$, and $8 \%$ ), and Poly-vinyl-Copolymers (PVC) with percent of modification of $(1,2$, and $3 \%)$ as a hybrid modification with $4 \%$ SBS (by weight of asphalt) were used with one type of mineral filler (Limestone dust), which was used as filler in mixtures. To estimate the parameters' effect on ITS, one was used in testing temperatures for indirect tensile strength test $(25){ }^{\circ} \mathrm{C}$ as recommended by ASTM (D6931-12). Likewise, three testing compaction types were used for fabrication indirect tensile strength test specimens (Marshall Hammer, Roller Compacter and Superpave Gyratory Compacter).

\section{Results and Discussion}

\subsection{Indirect Tensile Strength}

\subsubsection{Effect of Type of compaction on Tensile} strength

Indirect tensile strength test was performed to reveal the effect of compaction on the tensile strength of asphalt mixtures. Which are Superpave gyratory compactor, Marshall Hammer and roller compactor as shown in Fig. 6. It was illustrated that the compaction type had a significant effect on tensile strength magnitude. However, the results showed that fine and coarse mixture samples compacted with SGC had an enhancement in ITS by 10.9 and $36.58 \%$ for fine mixture and $8.7 \%$ and $30.3 \%$ for coarse mixture in comparison with Marshall and roller compactor respectively. Thus far, many reasons can explain the performance of HMA in correlation with type and effort of compaction. One of these causes is the impact compaction produced by Marshall Hammer to make densification for the specimens rather than producing re-orientation for the considered particles in contrast to SGC or relatively by the roller compactor which generates a shear effect could make re- 
arrangement for the grains imposing these particles in random arrangement rising in that manner the strength as a whole and tensile strength particularly. However, through the static compression technique, excessive pressures are essential to be applied to reach to the prerequisite material density, resulting in squeezing of the bitumen film, and crushing of mineral aggregates particles with the influence that the microstructure of the compacted mixes could be unlike the in situ material.

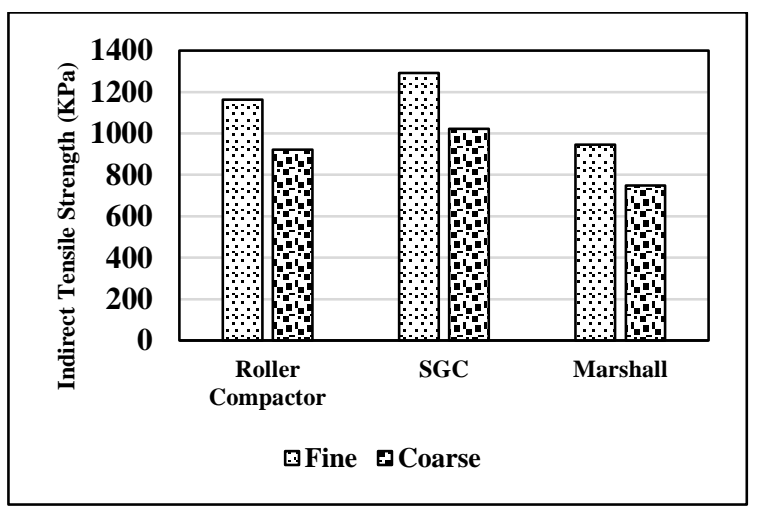

Figure (6) Effect of Compaction on Indirect Tensile Strength

\subsection{Effect of Modifiers on Indirect Tensile Strength}

There is an urgent need to find effective solutions to the problems of cracks in roads. Among these solutions are the use of additives to prevent or even delay the occurrence of cracks by mounting the tensile strength of hot mix asphalt used for paving. In recent decades, polymers have been the most prominent materials used to develop the performance of asphalt mixtures.

The two types of polymer modifiers were used to estimate their effect on tensile strength. SBS and PVC (as a hybrid modification with a $4 \%$ SBS); were used with deferent percent of modifications of 4,6 , and $8 \%$ for SBS and 1,2, and 3\% for hybrid modification. Results showed a significant effect on tensile strength for each type of modifiers. However, Fig. 7 exhibit the effect of SBS on tensile strength for the fine mix compacted with deferent types of compaction, adding 4,6 , and $8 \%$ of SBS can rise ITS by $3.54,6.87$ and $14.2 \%$ of the roller compacted non-modified asphalt mixture. Also, adding the same percents of SBS for SGC compacted specimens can exhibit an increment in the tensile strength by $3.2,6.1$, and 10.5 respectively in comparisons with non-modified asphalt mixtures. Furthermore, Marshall compacted samples show deferent increment in tensile strength by 3.6, 7.12 and $16.5 \%$ respectively. Generally, the effect of using SBS as a modifier to increase the tensile strength of asphalt mixtures may differ according to the type of compaction used, whereas the effect of modifiers is higher in Marshall, where there is an inverse relationship between the effect of the modifier and compaction techniques.

Likewise, directories gathered from experimental work illustrates that SBS modification for coarse mixtures affected the indirect tensile strength as revealed in Fig. 8 which shows that adding 4, 6, and $8 \%$ of SBS for roller compacted specimens can increase tensile strength by 2.6, 4.42 and 13.8\% respectively. Several types of research were conducted on the effect of polymers on the performance of asphalt mixtures, as well as this study which comes as a reflection of previous studies, as polymers involved their properties and behavior within the properties of asphalt binder, especially polymers which could increase the viscosity of the binder and therefore a certain amount of SBS can significantly improve bitumen cohesive strength rising the adhesion forces between binder and aggregate. The reasonable commentary is that modified binders liquefy less at increased temperatures (increased viscosity) and more elastic (less brittle) at decreased temperatures. Elastomers (such as SBS) are also supposed to develop the 'fatigue resistance' of asphalt attributes which is a significance for improved durability, i.e., less susceptible to fatigue-induced cracking through design life.

Furthermore, PVC had a significant effect on fracture properties represented by indirect tensile strength as illustrated in Fig. 8 and Fig. 9. Herein, the technique of modification which is adopted in this study, (i.e. Hybrid modification), shows a reliable increase in tensile properties for hot mix asphalt.

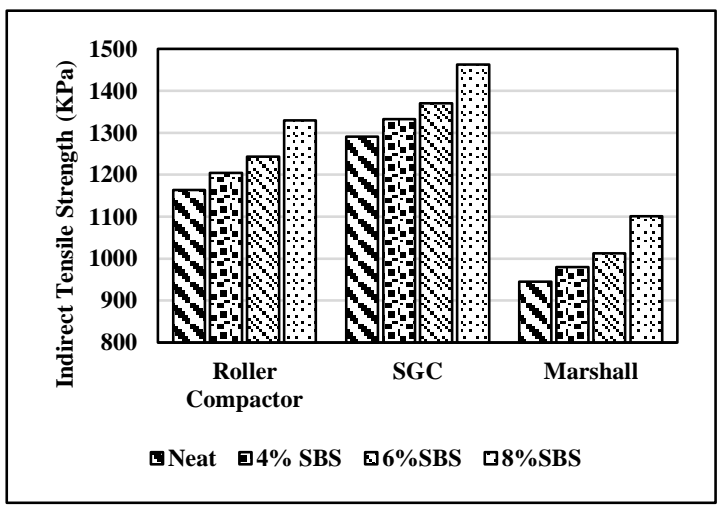

Figure (7) Effect of SBS on Indirect Tensile Strength for Fine Mixes under Deferent Types of Compaction

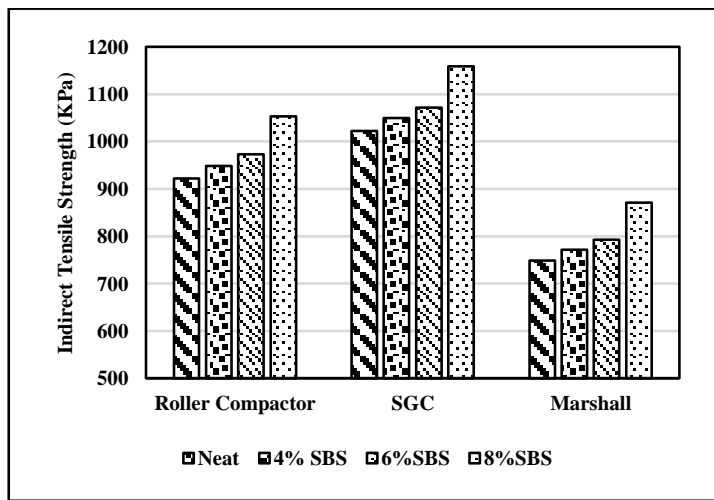

Figure (8) Effect of SBS on Indirect Tensile Strength for Coarse Mixes under Deferent Types of Compaction

Fig. 9 reveals the effect of hybrid modification on the indirect tensile strength for fine mixtures under deferent types of compaction. It is clear that each 
percent of PVC modification can improve the indirect tensile strength by $8.8,12.99$ and $17.2 \%$ respectively for roller compacted specimens; 8.5, 12.6 and $16.89 \%$ for SGC compacted specimens, and 8.93, 13 and $17.36 \%$ for Marshall compacted specimens.

The effect of hybrid modification on the indirect tensile strength for coarse mixtures under deferent types of compaction is exemplarily presented in Fig. 10. It is cleared that each percent of PVC modification can raise the indirect tensile strength by $5.2,8.7$ and $12.21 \%$ respectively for roller compacted specimens; 4.97, 7.2 and $11.8 \%$ for SGC compacted specimens, and $6.1,13$ and $17.36 \%$ for Marshall compacted specimens.

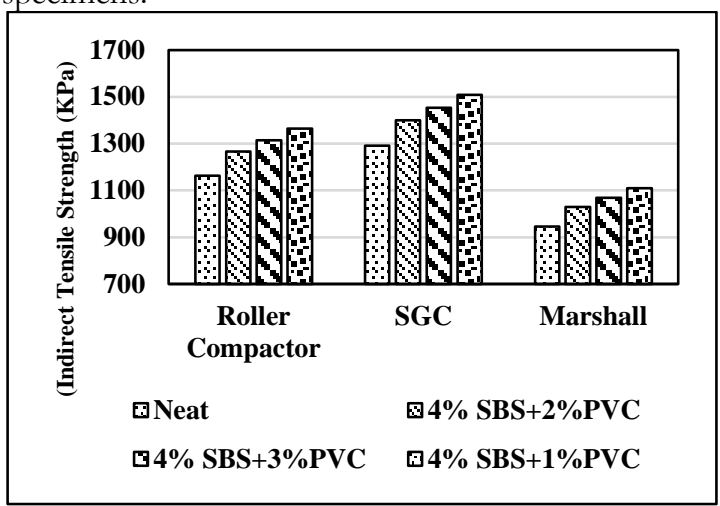

Figure (9) Effect of Hybrid on Indirect Tensile Strength for Fine Mixes under Deferent Types of Compaction

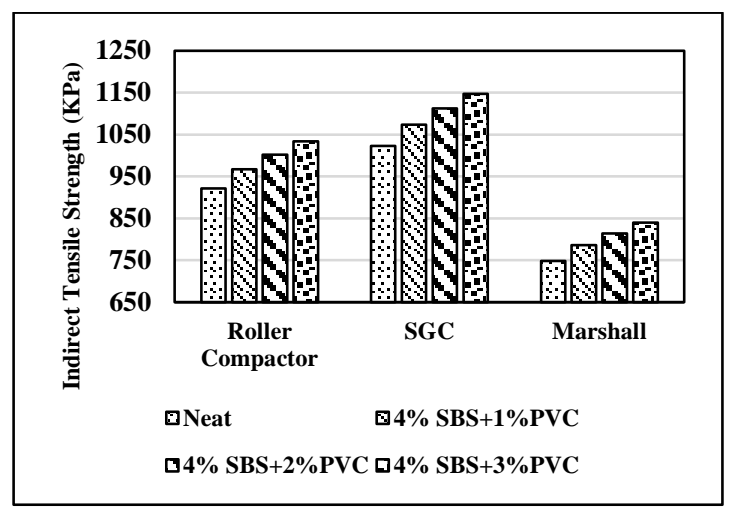

Figure (10) Effect of Hybrid on Indirect Tensile Strength for Coarse Mixes under Deferent Types of Compaction

The logical explanation for these results is adhesion between aggregate particles and asphalt binder, where the adhesion is an important asphalt property which determines asphalt performance and in-service life. In general, there is a difference in the effect of modifiers on the tensile strength results and according to the aggregate gradation of the mixtures so the fine mixtures showed a greater response to the polymer modifiers and in comparison with coarse mixtures due to the existence of the fine grains which have a larger surface area and thus a higher adhesion area of the improved asphalt binder, as well as fine mixtures have a greater amount of mortar which is the major cause in increasing tensile strength for hot mix asphalt.
4. Determination of Asphalt Mixture Stiffness through Indirect Tensile Tests

This study focuses on estimating the stiffness of hot asphalt mixtures through static indirect tensile tests according to ASTM D-6931. Especially the data from static tests which have been treated to obtain stiffness magnitudes through the implementation of Hondros theory. Also according to the empirical derivation, the formula could enable the researching centers, agencies, and laboratories that are not equipped with an appropriate device for dynamic modulus tests to evaluate the stiffness properties of the asphaltic material, by exclusively execution simple static tests.

\subsubsection{Stiffness Modulus Estimation by Hondros Theory}

Static modulus $\mathrm{E}_{\mathbf{s}}, \mathbf{H}$ could be determined by equation 5 , as soon as the vertical surface deformation (fattening) $\mathrm{U}_{\mathrm{y}}$ and the applied load $\mathrm{P}$ to the samples is calculated. However, considering that the stress-strain state was caused by the application of a uniform load, using Equation 6 made it managable to determine a value of $E_{s, H}$ at each spot, i.e., for each of available load-vertical displacement value. Fig. 11 shows the $\mathrm{E}_{\mathrm{s}, \mathrm{H}}$ emergence during ITS tests for the fine and coarse mixes with the optimum asphalt content at the standard test temperature. In particular, coarse gradation, lower modulus values and flatter curves, which could be gathering Fig. 12 to detailing the effect of gradation on Hondros stiffness.

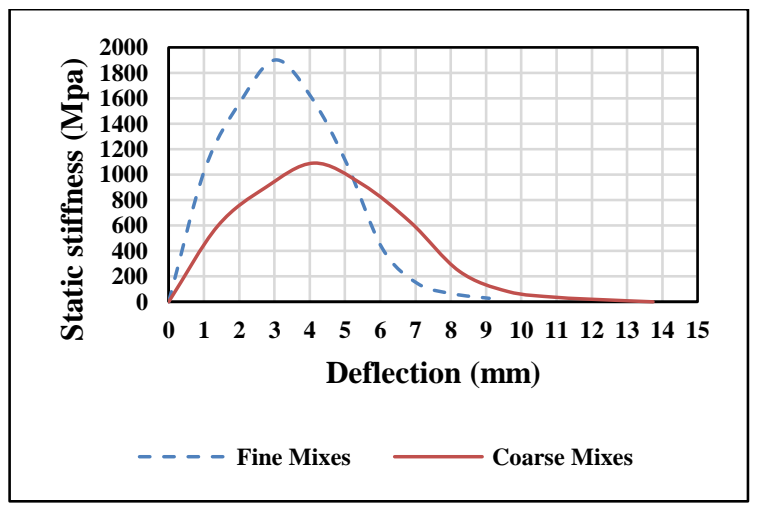

Figure (11) Hondros Stiffness vs. Surface Deflection in Specimens

Hence, fine mixes showed a higher static stiffness by $28.25 \%$ in comparison of coarse mixes. It was splended to specify that the maximum $\mathbf{E}_{\mathbf{s}, \mathbf{H}}$ values were recorded in harmonization with the magnitudes of maximum load (i.e., the load at splitting or collapse). It was particularly noticed that on average, for all samples and test circumstances, the higher values of $\mathrm{E}_{\mathbf{s}, \mathbf{H}}$ were determined as the vertical displacement was equalled to nearly the quarter vertical displacement to failure. This experimental substantiation where the material revealed a kind of early rigidity along the vertical plane, possibly caused by densification effects, which hence maximized the theoretical modulus $\mathrm{E}_{\mathrm{s}, \mathrm{H}}$ before the splitting occurred. Subsequently, and the reductions in $\mathrm{E}_{\mathbf{s}, \mathbf{H}}$ revealed the damage development within the specimen. 


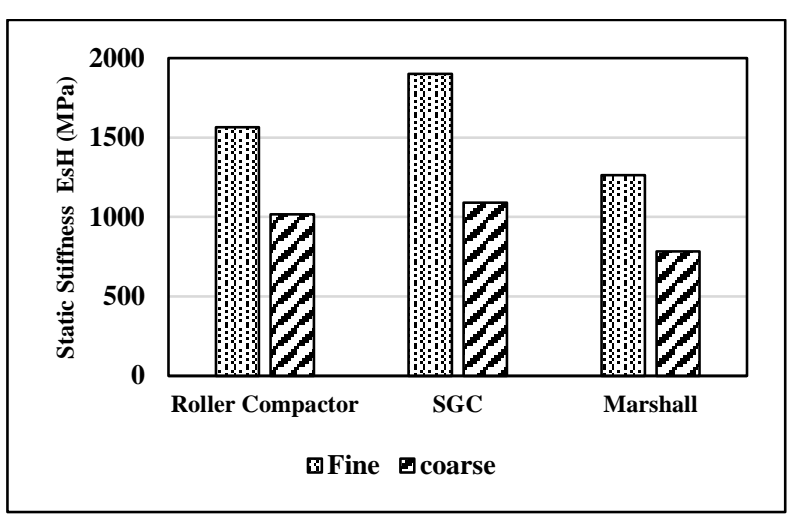

Figure (12) Gradation influence on Stiffness

\subsection{Effect of Modification on Static Modulus of Stiffness}

Through the fabrication of the specimens, it revealed that the polymer-modified mixes were more difficult to compact or even mix. Therefore, any percent of modifiers can significantly increase the stiffness of the mix as a result to raise the viscosity of the asphalt binder. During tests' analysis, it is wellknown that polymer modification had a significant effect on static stiffness of fine mixtures as shown in Fig. 13, which illustrates the response of the asphalt mixture during loading that adding 4,6 , and 8 percent of SBS could increase static stiffness by 53.9, 209.6, and $302.4 \%$ respectively for roller compacted fine mixes and 58, 220, and 379.3\% for SGC compacted mixes. Furthermore, SBS raised the stiffness modulus by $52.3,188$, and $295 \%$ for Marshall compacted mixes.

Moreover, hybrid modification shows a similar effect on the static stiffness it can be sensed through the results obtained from the same Fig. 13 mentioned above. Using hybrid-modification can develop the stiffness of the asphalt mixture. However, The results indicate that using 1,2 and 3\% PVC can magnify the stiffness of mixtures by $41.2,199.8 \%$ and 262.6 for roller compacted mixtures and 133.4, 212.1 and $354 \%$ for SGC fine compacted mixtures, while there is a stringent increasing by $133.4,189.2$ and $354 \%$ for Marshall fine compacted mixes.

On the other hand, the results obtained from laboratory experiments and analyzed empirically by Hondros' theory showed that the effect of the polymer modification was highly significant when used with coarse mixes. Generally, using the proposed percents of SBS and hybrid modification contributed significantly to the increment of the static stiffness modulus, as shown in Fig. 14. However, using 4, 6 and $8 \%$ SBS have increased the stiffness of roller coarse compacted mixes by $79.4,250.8$ and $510.8 \%$. While the stiffness of the SGC coarse compacted specimens was increased by $66.7,189.2$, and $392.6 \%$ respectively. Moreover, static stiffness modulus of Marshall coarse compacted specimens was increased by $57.8,241.5$, and $420.6 \%$ respectively.

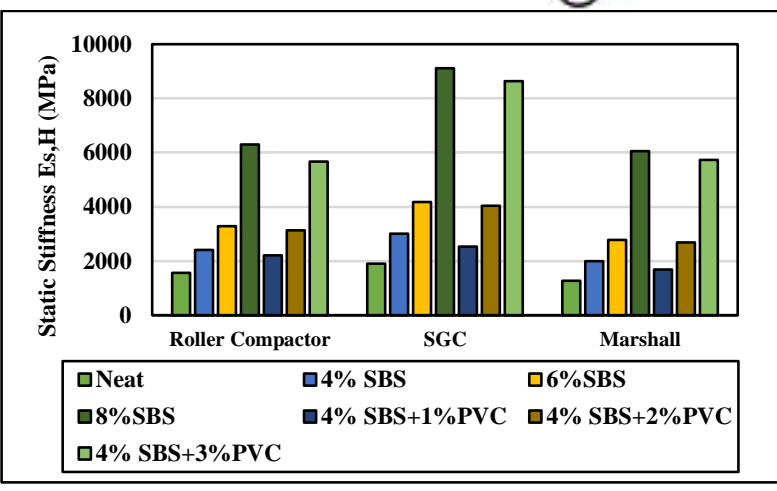

Figure (13) Effect of Polymers on Static Stiffness for Fine Mixtures under Deferent Compaction Types

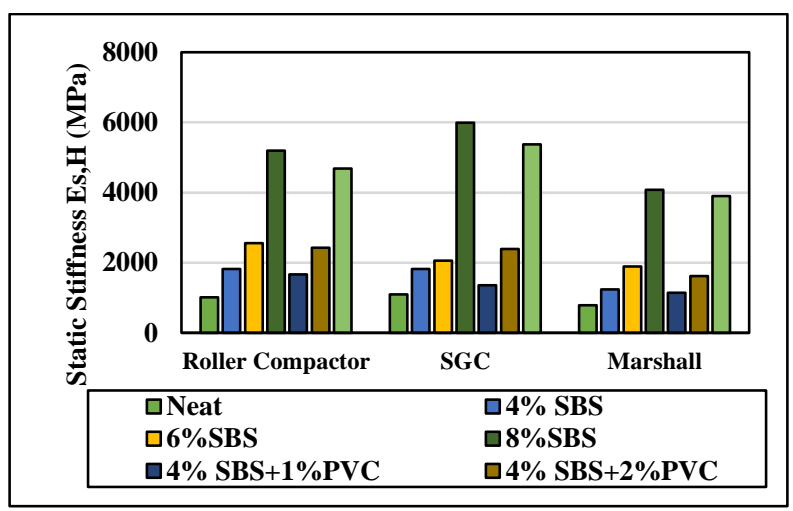

Figure (14) Effect of Polymers on Static Stiffness for Coarse Mixtures under Deferent Compaction Types

Hybrid modification with the proposed percents can rise static stiffness modulus in comparisons with non-modified mixtures by $64,238.2,360.1,24,218.8$, $392.6,146.63,207.1$ and $398.2 \%$ for roller, SGC, and Marshall coarse compacted specimens.

The results obtained from the Figures above showed clearly that the type of mixture and the compaction methods had a significant effect on the effectiveness of using the modifiers. Therefore, the coarse mixtures with the Marshall compaction are capable to demonstrate the response of the asphalt binder to the polymer modification which were used in the study due to the poor reorientation of the grains particles, and that make the mixture resistance mainly based on the mortar and the asphalt binder.

\section{The relation between the Static} Stiffness and the Indirect Tensile Strength

As the study needs to find a relationship between the modulus of static stiffness and indirect tensile strength of hot asphalt mixtures concerning the compaction percentage of polymeric modifiers type, a relationship was drawn between these variables. It was found that the relationship between the coefficient of static strength and tensile strength were linear relations of all SBS-modified compacted specimens. however, Fig. 15 illustrates that the reliable relationships with a high coefficient of determination $\left(\mathrm{R}^{2}\right)$ of 97.4 , 98.2, and $98.4 \%$ for SGC, roller and Marshall compacted specimens respectively. 


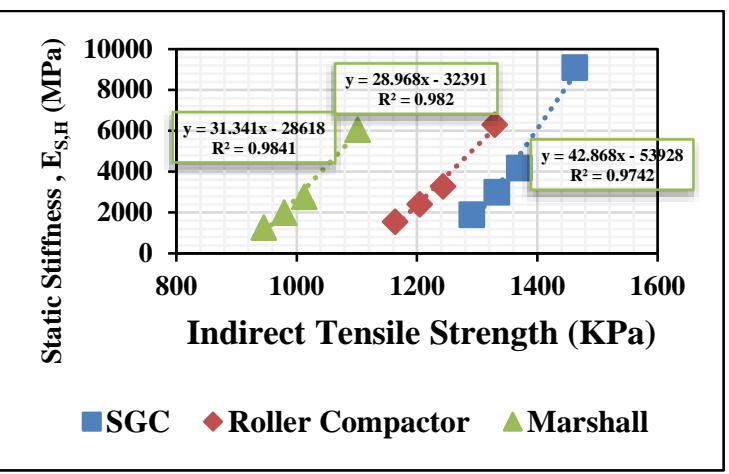

Figure (15) Relation between Indirect Tensile Strength and Static Stiffness for SBSModified Mixtures

In the same manner, as previously illustrated, the relations were drawn to identify their shaps of mixtures improved by the hybrid modifiers. However, the shape of these relations differed from the relationships which developed for SBS-modified. Fig. 16 shows that the shapes take the form of exponential relationship with high determination coefficients $\left(\mathrm{R}^{2}\right)$ of $86,90.4$, and $85.1 \%$ for SGC, roller and Marshall compacted specimens respectively. The simple relationships that were derived in this study may be useful for predicting static modulus of stiffness by finding the indirect tensile strength, especially in laboratories that do not have the special equipment to the invention any of the previous variables.

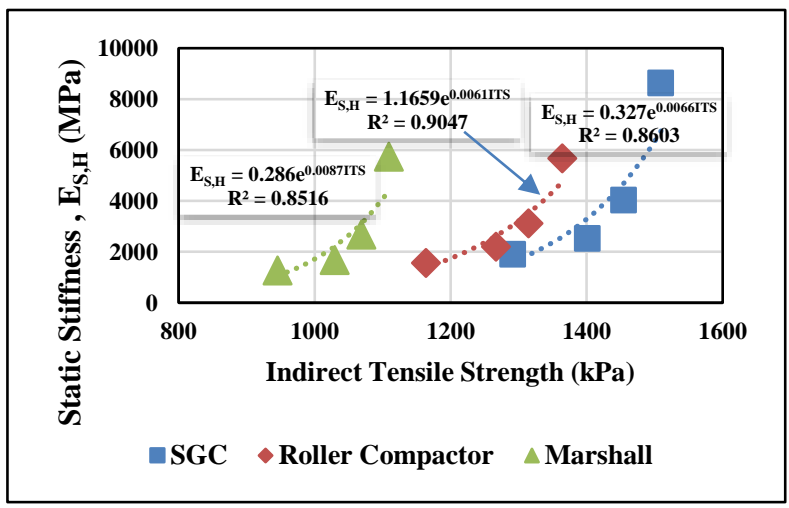

Figure (16) Relation between ITS and Static Stiffness for Hybrid-| Modified Mixtures

\section{Fracturing index as criteria for Fracturing Properties}

The concentration in the past decades has been to make asphalt mixtures more affordable. This has led to the augmented use of binder perfecter, amelioration, and modifications. Accordingly, the predominate grievance was that the contemporary mixtures were more susceptible to fracturing. There is a crucial necessity for a useful cracking test for monotony use in the design of the method of the mix. This paper adopted the developed indirect tensile asphalt embedded with a cracking test as a name of (IDEAL-CT). The IDEAL-CT is stereotypically operational in normal conditions such as room temperature, $62 \mathrm{~mm}$ high, $100.1 \mathrm{~mm}$ diameter, cylindrical briquette, and with the typical loading rate of $50 \mathrm{~mm} / \mathrm{min}$.

The most predominant issue for IDEAL-CT test was to produce performance-related concerns the cracking behavior from the recoded load-displacement curves. The procedure of the new fracturing parameter is inspired by the renowned Paris' law [32] and the effort had been done by Bazant and Prat[33] and the derivation of the study which was conducted by Fujie Zhou et.al. [34] for crack propagation explained in equation 6:-

$$
F_{\text {index }}=t \times \frac{G_{f}}{\frac{P}{\Delta u}} \times \frac{\Delta u}{D}
$$

Where:

$\mathrm{P} / \Delta \mathrm{u}=$ a modulus parameter or the slope of the load-displacement curve),

$G_{f}=$ Fracture Energy is the work of fracture (the area of the load vs. vertical displacement curve) divided by the area of cracking face., and

$\Delta \mathrm{u} / \mathrm{D}=\mathrm{a}$ strain tolerance parameter or the deformation tolerance under a load, noting that $F_{I}$ can vary from 1 to 1000 with a higher number representing enhanced crack resistance.

\subsection{Sensitivity of Fracturing Index to} Aggregate Gradation

Fig. 17 shows clearly the effect of gradation on the fracturing index, where fine mixtures show a higher fracture index in comparisons in the coarse mixtures by $9.89,10.29,14.87 \%$ for roller, SGC and Marshall compacted specimens. However, From the previously mentioned increase values, the effect of the type of compaction can be a critical point in that increase. Therefore, the capability of cracking propagation within the asphalt mix depends on several factors, such as gradation and rheological properties of asphalt binder. The fine gradation contains a higher quantity of grains that fill the gaps between the large particles Making the mixture a coherent mass in front of the stresses generated by the load.

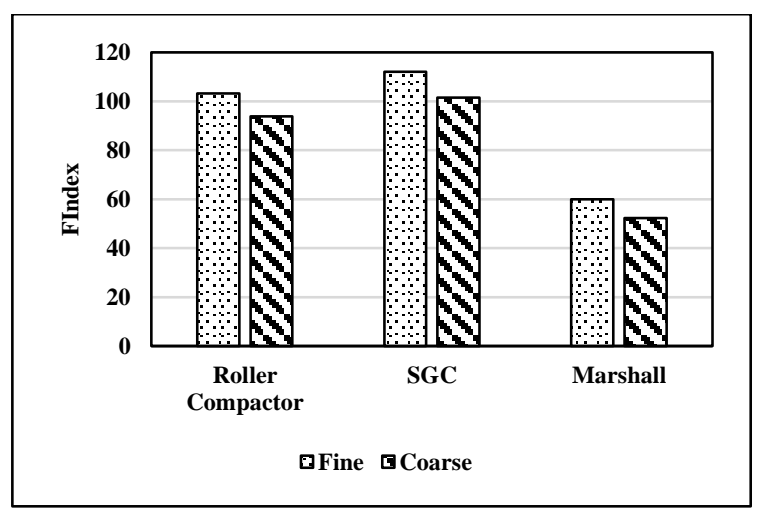

Figure (17) Effect of Gradation on $F_{\text {Index }}$ under Deferent Types of Compaction 


\section{2 influence of Tensile Strength on Fracturing index}

The laboratory results obtained from the experiments showed clearly that there is a definite relationship between the indirect tensile strength and the fracturing index for describing the spread of cracks in the SBS- modified asphalt mixtures as shown in Fig. 18 below. These relations took the form of linear relationships with coefficients of determination up to 95.3, 94.7, and 96.3. also, Fig. 18 shows the effect of SBS on the Fracturing index. However, using 4,6 and $8 \%$ of the SBS decreased the fracturing index by 31.5 , 37.5 , and $72 \%$ for SGC compacted asphalt, and 34.6, 42.6 , and $75.9 \%$ for roller compacted asphalt, also by 26.8, 30.5, and $69.1 \%$ for Marshall.

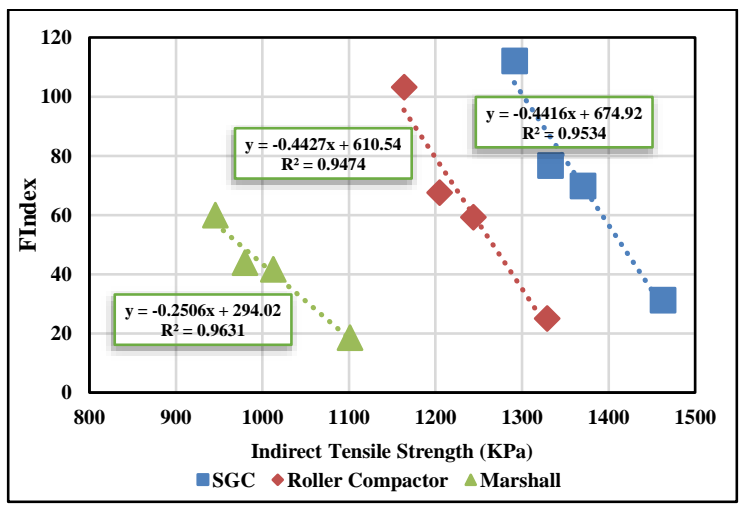

Figure (18) Relation between Indirect Tensile Strength and $F_{\text {index }}$ for SBS-Modified Mixtures

Unequivocally, Fig. 19 shows that hybrid modification can reduce the resistance to the propagation of cracks. As well as indicates that the addition of hybrid modification with the proposed percents in this study was capable to reduce the fracture index of by $44.9,76.1$, and $85.7 \%$ for SGC compacted specimens. Also, fracturing index was reduced by $46.7,78.8$, and $88.6 \%$ for roller compacted specimens, 44.9, 76.1, and 86.3 for Marshall compacted specimens. Furthermore, Fig. 19 exhibit the relationships between the indirect tensile strength and the fracturing index which in somehow follow a linear form with high coefficients of determinations of 97.9, 98, and 98.1 for SGC, roller, and Marshall compacted specimens.

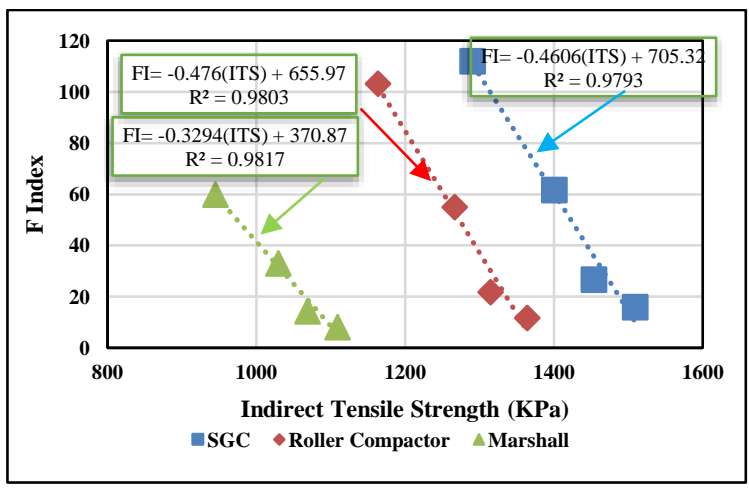

Figure (19) Indirect Tensile Strength vs. $F_{\text {index }}$ for Hybrid-Modified Mixtures

\section{Conclusions}

This paper tried to investigate the effect of aggregate gradation, compaction types, and polymer modification on the fracture properties for hot mix asphalt. Therefore, through this study it is possible to summarize the following facts:

- Aggregate gradation has a key role in changing the indirect tensile strength. However, the results showed that fine and coarse mixture samples compacted with SGC had an enhancement in ITS by 10.9 and $36.58 \%$ for fine mixture and $8.7 \%$ and $30.3 \%$ for coarse mixture in comparison with Marshall and roller compactor respectively. Moreover, Fine mixes showed a higher static stiffness by $28.25 \%$ in comparison of coarse mixes.

- Using 4, 6, and $8 \%$ of SBS can rise ITS by 3.54, 6.87 and $14.2 \%$ of the roller compacted nonmodified asphalt mixture and adding the same percents of SBS for SGC compacted specimens can exhibit an increment in the tensile strength by 3.2, 6.1, and 10.5 respectively in comparisons with non-modified asphalt mixtures. PVC modification can improve the indirect tensile strength by 8.8 , 12.99 and $17.2 \%$ respectively for roller compacted specimens; 8.5, 12.6 and $16.89 \%$ for SGC compacted specimens; and 8.93, 13 and $17.36 \%$ for Marshall compacted specimens.

- Using 4, 6, and 8 percent of SBS could increase static stiffness by 53.9, 209.6, and 302.4\% respectively for roller compacted fine mixes and 58, 220, and $379.3 \%$ for SGC compacted mixes. Furthermore, SBS raised the stiffness modulus by 52.3, 188, and 295\% for Marshall compacted mixes. Using hybrid-modifier can improve the stiffness of the asphalt mixture. However, The results indicate that using 1,2 and 3\% PVC can magnify the stiffness of mixtures by $41.2,199.8 \%$ and 262.6 for roller compacted mixtures and 133.4, 212.1 and $354 \%$ for SGC compacted mixtures, while there is a stringent increasing by $133.4,189.2$ and 354\% for Marshall compacted mixes.

- The present research work focuses on defining a proper correlation between the modulus evaluated through the static test (Hondros stiffness) and the indirect tensile strength, which were reliable linear relationships with a high coefficient of determination $\left(\mathrm{R}^{2}\right)$ of $97.4,98.2$, and $98.4 \%$ for SGC, roller and Marshall compacted specimens respectively, and an exponential relationship for hybrid modified mixtures with determination coefficients $\left(\mathrm{R}^{2}\right)$ of $86,90.4$, and $85.1 \%$ for SGC, roller and Marshall compacted specimens respectively.

- Gradation and compaction method had a significant effect on the fracturing index, where fine mixtures show a higher fracture index in comparisons in the coarse mixtures by $9.89,10.29$, $14.87 \%$ for roller, SGC and Marshall compacted specimens. 


\section{Acknowledgements}

Authors wish to acknowledge assistance of $\mathrm{Al}$ Nahrain University, College of Engineering's faculty and personnel who have been like mentors throughout our work in the asphalt laboratory. Those people have provided the authors with the inspiration to undertake the work.

\section{References}

[1] A. Al-Hadidy and T. Yi-qiu, "Effect of styrenebutadiene-styrene on the properties of asphalt and stone-matrix-asphalt mixture," Journal of Materials in Civil Engineering, vol. 23, pp. 504-510, 2010.

[2] M. A. H. Al-Shaybani, "Investigation on Tensile Strength Ratio (TSR) Specimen to Predict Moisture Sensitivity of Asphalt Pavements Mixture and Using Polymer to Reduce Moisture Damage," Journal of University of Babylon, vol. 25, pp. 732-743, 2017.

[3] E. Chailleux, C. De La Roche, and J.-M. Piau, "Modeling of complex modulus of bituminous mixtures measured in tension/compression to estimate secant modulus in indirect tensile test," Materials and structures, vol. 44, pp. 641-657, 2011.

[4] P. Liu, J. Hu, D. Wang, M. Oeser, S. Alber, W. Ressel, et al., "Modelling and evaluation of aggregate morphology on asphalt compression behavior," Construction and Building Materials, vol. 133, pp. 196-208, 2017.

[5] F. K. Hamed, "Evaluation of fatigue resistance for modified asphalt concrete mixtures based on dissipated energy concept," Technische Universität Darmstadt, 2010.

[6] F. L. Roberts, Kandhal, P. S., Brown, E. R., Lee, D. Y., and Kennedy, T. W. , "Hot mix asphalt materials, mixture design and construction.2nd Ed. Lanham, Maryland.," (1996).

[7] C. Chen, "Rheological performance evaluation of asphalt modified with bio-based polymers," Graduate Theses and Dissertations, Iowa State University Capstones, Theses and Dissertations, 2015.

[8] H. Yaacob, S. N. Yaacop, and M. K. I. Mohd, "Study the Performance of Modified Asphalt Mixture Using Styrene Butadiene Styrene."

[9] N. M. Asmael and M. Q. Waheed, "Investigation of Using Polymers to Improve Asphalt Pavement Performance," American Scientific Research Journal for Engineering, Technology, and Sciences (ASRJETS), vol. 39, pp. 38-48, 2018.

[10] A. H. Abed, "Required Criteria for Implementation of the Superpave System in Local Pavement Design," Ph. D. Thesis, Civil Engineering department, Collage of Engineering, University of Baghdad, 2010.

[11] G. Polacco, S. Filippi, F. Merusi, and G. Stastna, "A review of the fundamentals of polymermodified asphalts: Asphalt/polymer interactions and principles of compatibility," Advances in Colloid and Interface Science, vol. 224, pp. 72-112, 2015.

[12] S. Tayfur, H. Ozen, and A. Aksoy, "Investigation of rutting performance of asphalt mixtures containing polymer modifiers," Construction and Building Materials, vol. 21, pp. 328-337, 2007.

[13] B. Sengoz and G. Isikyakar, "Evaluation of the properties and microstructure of SBS and EVA polymer modified bitumen," Construction and Building Materials, vol. 22, pp. 1897-1905, 2008.

[14] M. Gilchrist, Performance Related Test Procedures for Bituminous Mixtures: Proceedings of the Workshop on Performance Related Test Procedures for Bituminous Mixtures, Dublin 6-7 November 1997: Boole Press, 1997.

[15] A. Hartman, M. Gilchrist, and G. Walsh, "Effect of mixture compaction on indirect tensile stiffness and fatigue," Journal of transportation engineering, vol. 127, pp. 370-378, 2001.

[16] J. W. Button, D. N. Little, V. Jagadam, and O. J. Pendleton, "Correlation of selected laboratory compaction methods with field compaction," Transportation Research Record, 1994.

[17] J. Harvey and C. L. Monismith, "Effects of laboratory asphalt concrete specimen preparation variables on fatigue and permanent deformation test results using strategic highway research program a-003a proposed testing equipment," Transportation Research Record, 1993.

[18] M. Barman, R. Ghabchi, D. Singh, M. Zaman, and S. Commuri, "An alternative analysis of indirect tensile test results for evaluating fatigue characteristics of asphalt mixes," Construction and Building Materials, vol. 166, pp. 204-213, 2018.

[19] Z. Wu, L. N. Mohammad, L. Wang, and M. A. Mull, "Fracture resistance characterization of superpave mixtures using the semi-circular bending test," Journal of ASTM International, vol. 2, pp. 1-15, 2005.

[20] I. ARA, "Guide for mechanistic-empirical design of new and rehabilitated pavement structures," ed: Transportation Research Board of the National Academies. Washington, DC, 2004.

[21] AASHTO, "Standard practice for superpave volumetric design for asphalt mixtures," 2015.

[22] F. Zhou, D. Newcomb, C. Gurganus, S. Banihashemrad, E. S. Park, M. Sakhaeifar, et al., "Experimental design for field validation of laboratory tests to assess cracking resistance of asphalt mixtures," NCHRP Project, pp. 9-57, 2016.

[23] Hondros, "The evaluation of poisson's ratio and the modulus of materials of a low tensile resistance by the brazilian (indirect tensile) test with particular reference to concrete.," Aust. J. Appl. Sci., vol. 10(3), pp. 243-268, 1959.

[24] G. Cerni, E. Bocci, F. Cardone, and A. Corradini, "Correlation between asphalt mixture stiffness determined through static and dynamic indirect tensile tests," Arabian Journal for Science and Engineering, vol. 42, pp. 1295-1303, 2017.

[25] J. Almudaiheem and F. Al-Sugair, "Effect of loading magnitude on measured resilient modulus of asphaltic concrete mixes," Transportation Research Record, 1991.

[26] T. Pan, E. Tutumluer, and S. H. Carpenter, "Effect of coarse aggregate morphology on permanent deformation behavior of hot mix 
asphalt," Journal of transportation engineering, vol. 132, pp. 580-589, 2006.

[27] F. L. Roberts, P. S. Kandhal, E. R. Brown, D.-Y. Lee, and T. W. Kennedy, "Hot mix asphalt materials, mixture design and construction," 1991.

[28] C.-T. Lim, S.-A. Tan, and T.-F. Fwa, "Specimen size effects on the diametrical mechanical testing of cylindrical asphalt mixes," Journal of testing and evaluation, vol. 23, pp. 436-441, 1995.

[29] SCRB, "State Commission of Roads and Bridges, Standard Specification for Roads \& Bridges, Ministry of Housing \& Construction, Iraq.," 2003.

[30] A. Standard, "D6931," Standard test method for indirect tensile (IDT) strength of bituminous mixtures. ASTM, West Conshobocken, PA, 2012.
[31] A. Graziani, M. Bocci, and F. Canestrari, "Complex Poisson's ratio of bituminous mixtures: measurement and modeling," Materials and structures, vol. 47, pp. 1131-1148, 2014.

[32] P. Paris and F. Erdogan, "A critical analysis of crack propagation laws," Journal of basic engineering, vol. 85, pp. 528-533, 1963.

[33] Z. P. Bazant and P. C. Prat, "Effect of temperature and humidity on fracture energy of concrete," ACI Materials Journal, vol. 85, pp. 262271, 1988.

[34] F. Zhou, S. Im, L. Sun, and T. Scullion, "Development of an IDEAL cracking test for asphalt mix design and QC/QA," Road Materials and Pavement Design, vol. 18, pp. 405-427, 2017. 